\title{
Study of Subclinical Atherosclerosis in Patients with Type 2 Diabetes Mellitus
}

Alhoussein Alsayed AbdelAal*, Alshabrawy M. Abdelnabi

Department of Internal Medicine, Faculty of Medicine, Zagazig University, Egypt

* Corresponding author: Alhoussein Alsayed AbdelAal, Mobile: (+2) 01022073791, E mail: alhala1982@ gmail.com

\begin{abstract}
Background: Patients with type 2 diabetes mellitus (T2DM) are at increased risk of atherosclerosis. The early recognition of atherosclerosis at its subclinical stages can slow or prevent progression to atherosclerotic diseases, including coronary artery disease, cerebrovascular disease, and peripheral arterial disease.

Objective: Identification of the relationship between T2DM and subclinical atherosclerosis and to explore factors that can be associated with a high risk of subclinical atherosclerosis.

Patients and Methods: We recruited 75 participants among whom 50 T2DM while 25 were controls. Patients with T2DM were subdivided into two equal groups, well-controlled and uncontrolled. After complete history and examination, investigations including fasting and 2-hour postprandial blood glucose, high sensitive C-reactive protein (hs-CRP), and serum triglyceride (TG) levels were obtained. All participants underwent duplex ultrasound that was used to measure carotid intima-media thickness (cIMT) as a biomarker of subclinical atherosclerosis.

Results: Uncontrolled diabetics had increased cIMT than well-controlled diabetics and well-controlled diabetics had increased cIMT than non-diabetics. There was a highly significant positive correlation between cIMT and duration of diabetes in both well-controlled and uncontrolled diabetic groups. In the uncontrolled diabetic group only, there was a highly significant positive correlation between cIMT and each of hs-CRP and TG levels.

Conclusion: The risk of subclinical atherosclerosis is higher in type 2 diabetic patients especially in those with uncontrolled diabetes. In uncontrolled diabetics, subclinical atherosclerosis is associated with hypertriglyceridemia and elevated hs-CRP level.
\end{abstract}

Keywords: Atherosclerosis, High Sensitive C - reactive, Triglyceride, Type 2 Diabetes Mellitus.

\section{INTRODUCTION}

According to the Diabetes Atlas ( $9^{\text {th }}$ edition), the global prevalence of diabetes is estimated at 463 million and is expected to rise to 578 million by 2030. In Egypt, there are about 8.9 million people with diabetes, and are expected to reach 11.9 million by 2030 (1). Macrovascular complications are the leading cause of morbidity and mortality in type 2 diabetes patients $(\mathrm{T} 2 \mathrm{DM})^{(2)}$. Patients with type 2 diabetes have a 2 to 8 fold increased risk of developing total vascular disease compared to non-diabetic patients of the same age, gender, and ethnicity ${ }^{(3)}$. Atherosclerosis and its consequences are a major symptom of large blood vessel diabetes complications ${ }^{(4)}$.

Atherosclerosis is a chronic, progressive inflammatory disease preceded by a prolonged subclinical stage characterized by an increased thickness of the inner and middle membrane of the arterial wall (intima-media thickness-IMT) with inflammation of the artery wall ${ }^{(5)}$.

This study was conducted to explore subclinical atherosclerosis and its relevant determinants in patients with T2DM.

\section{PATIENTS AND METHODS}

This cross-sectional study was carried out in the Internal Medicine Department, Faculty of Medicine, Zagazig University Hospitals.

75 individuals aged $\geq 40$ years were recruited to the study. They were divided into three equal groups: 25 healthy individuals represented the control group, 25 patients with T2DM whose glycosylated hemoglobin (HA1c) was $<7 \%$ (well-controlled diabetics), and 25 patients with T2DM whose HA1c was $\geq 7 \%$ (uncontrolled diabetics).

Exclusion criteria: We excluded patients with type 1 DM, patients with clinically manifested atherosclerosis, and those who harbored any cause that may elevate high sensitive C-reactive protein (hs-CRP) as infection, inflammation, surgery, renal failure, and malignancy.

All individuals were subjected to full history taking, thorough physical examination, and biochemical analysis for fasting plasma glucose (FPG), 2-hours postprandial blood glucose (PPG), HA1c, triglycerides (TG), and hs-CRP.

Two venous blood samples were collected from each individual after 12 hours of overnight fasting. The first sample was collected in a glass tube containing Ethylene diamine tetra acetic acid (EDTA) for HA1c using the Bio-Rad D-10 high-performance liquid chromatography (Bio-Rad Laboratories, CA, USA). The second sample was collected in a dry tube without anticoagulant then it was immediately centrifuged and kept in a freezer at minus 80 degrees Celsius. It was handled by the automated chemiluminescence method with the IMULITE DPC Medlab system. Serum triglycerides were measured by the enzymatic colorimetric test with lipid clearing factor using the Beckman DxC800 general chemistry analyzer (Beckman Coulter, Fullerton, CA, USA). Measurement 
of hs-CRP was done by an enzyme-linked immunosorbent assay (ELISA) based on purified protein and polyclonal anti-C-reactive protein antibodies (Calbiochem, San Diego, CA, USA). ). On the $2^{\text {nd }}$ day, two venous blood samples were collected, one after overnight fasting of 8 hours for FPG measurement and the other 2 hours breakfast for PPG measurement. FPG and PPG were measured using the glucose oxidase and peroxidase method.

Carotid intima-media thickness (cIMT) is a marker that can be used to identify subclinical atherosclerotic disease. Because it can be measured in a relatively simple and non-invasive way, it is well suited for use in large-scale population studies ${ }^{(6)}$.

Ultrasound of the carotid arteries was done with a B-mode Duplex ultrasound (SONO 5500, HP, USA). The cIMT was assessed at $1 \mathrm{~cm}$ from the carotid bulb on the left and right sides. The mean cIMT of each artery was calculated by taking the average of the left and right sides in each individual ${ }^{(7)}$.

\section{Ethical approval:}

We obtained approval for performing this study from the Institutional Review Board, Zagazig Faculty of Medicine and written informed consents were taken from all enrolled individuals.

\section{Statistical analysis}

All data were collected, tabulated, and statistically analyzed using SPSS 22.0. Categorical data were described as a percentage and continuous data were described as the mean \pm standard deviation. For calculation of the difference between qualitative variables, we used Chi-square test $\left(\chi^{2}\right)$. One way analysis Of variance (ANOVA) test supplemented with Tukey HSD (Honestly Significant Difference) or post hoc test was used to compare between more than two dependent groups of normally distributed variables, while Friedman's ranks test was used for non-normally distributed variables. All statistical comparisons were two-tailed. $\mathrm{P}$-value $\leq 0.05$ was considered to be statistically significant and $\mathrm{P}$-value $<0.01$ was considered to be highly statistically significant. Correlations between variables were done by using the Pearson correlation coefficient.

\section{RESULTS}

Our study included 11 males and 14 females with a mean age of 47.28 years for the control group, 13 males and 12 females with a mean age of 50.08 years for the well-controlled diabetic group, and 12 males and 13 females with a mean age of 53.76 years for the uncontrolled diabetic group.

There was a highly significant difference among the three studied groups regarding age, body mass index (BMI), systolic blood pressure (SBP), and DM duration. No significant difference among the three studied groups was found regarding sex and diastolic blood pressure (DBP) (Table 1).
Table (1): Demographic data and clinical characteristics of the three studied groups

\begin{tabular}{|c|c|c|c|c|c|c|}
\hline \multicolumn{2}{|c|}{$\begin{array}{l}\text { The studied } \\
\text { parameter }\end{array}$} & $\begin{array}{l}\text { Control } \\
\text { Group } \\
(\mathrm{N}=25)\end{array}$ & $\begin{array}{c}\text { Well- } \\
\text { controlled } \\
\text { diabetic } \\
\text { Group } \\
(\mathrm{N}=25)\end{array}$ & $\begin{array}{c}\text { Uncontrolled } \\
\text { diabetic } \\
\text { Group } \\
(\mathrm{N}=25)\end{array}$ & $\mathrm{F} / \chi^{2}$ & $\mathbf{P}$ \\
\hline \multicolumn{2}{|c|}{$\begin{array}{l}\text { Age (years) } \\
\text { Mean } \pm \text { SD }\end{array}$} & $\begin{array}{c}47.28 \pm \\
5.56\end{array}$ & $\begin{array}{c}50.08 \pm \\
4.74\end{array}$ & $\begin{array}{c}53.76 \pm \\
6.76\end{array}$ & 7.983 & 0.001 \\
\hline \multirow[t]{2}{*}{$\operatorname{Sex}$} & Male & $\begin{array}{c}11 \\
(44 \%)\end{array}$ & $13(52 \%)$ & $12(48 \%)$ & \multirow[t]{2}{*}{0.120} & \multirow[t]{2}{*}{0.729} \\
\hline & Female & $\begin{array}{c}14 \\
(56 \%)\end{array}$ & $\begin{array}{c}12 \\
(48 \%)\end{array}$ & $13(52 \%)$ & & \\
\hline \multicolumn{2}{|l|}{$\begin{array}{l}\text { BMI } \\
\left(\mathrm{kg} / \mathrm{m}^{2}\right)\end{array}$} & $\begin{array}{c}24.62 \pm \\
2.74\end{array}$ & $\begin{array}{c}27.17 \pm \\
2.4 \\
\end{array}$ & $\begin{array}{c}27.96 \pm \\
2.48 \\
\end{array}$ & 11.777 & $<0.001$ \\
\hline \multirow{2}{*}{\begin{tabular}{|l|}
$\mathbf{A B P}$ \\
$(\mathbf{m m H g})$ \\
$(\mathrm{Mean} \pm$ \\
$\mathrm{SD})$ \\
\end{tabular}} & Systolic & $\begin{array}{r}118.88 \\
\pm 9.32 \\
\end{array}$ & $\begin{array}{c}124.4 \pm \\
7.54\end{array}$ & $\begin{array}{c}126.84 \pm \\
3.79\end{array}$ & 7.890 & 0.001 \\
\hline & Diastolic & $\begin{array}{c}78.28 \pm \\
8.83 \\
\end{array}$ & $\begin{array}{c}79.96 \pm \\
7.02 \\
\end{array}$ & $\begin{array}{c}83.24 \pm \\
7.29 \\
\end{array}$ & 2.648 & 0.078 \\
\hline \multicolumn{2}{|c|}{$\begin{array}{l}\text { Duration of DM } \\
\text { (years)Mean } \pm \\
\text { SD } \\
\end{array}$} & ---------- & $\begin{array}{c}6.48 \pm \\
3.46 \\
\end{array}$ & $\begin{array}{c}13.6 \pm \\
4.35 \\
\end{array}$ & 103.283 & $<0.001$ \\
\hline
\end{tabular}

ABP: arterial blood pressure; BMI: body mass index; DM: diabetes mellitus; $\mathrm{N}$ : number of subjects; $\chi^{2}$ : Chi-square test; $\mathrm{P}<$ 0.05: statistically significant; $\mathrm{P}<0.01$ : highly statistically significant.

Regarding TG, hs-CRP, and cIMT, there was a highly significant difference among the three studied groups (Table 2).

Table (2): Distribution of TG, hs-CRP, and cIMT among the three studied groups

\begin{tabular}{|c|c|c|c|c|c|}
\hline & $\begin{array}{c}\text { Control } \\
\text { Group } \\
(\mathrm{N}=25)\end{array}$ & $\begin{array}{c}\text { Well- } \\
\text { controlled } \\
\text { diabetic } \\
\text { Group } \\
(\mathrm{N}=25)\end{array}$ & $\begin{array}{c}\text { Uncontrolled } \\
\text { diabetic } \\
\text { Group } \\
(\mathrm{N}=25)\end{array}$ & F test & P value \\
\hline TG & $137.92 \pm$ & $160.45 \pm$ & $234.18 \pm$ & 34.340 & $<0.001$ \\
(ng/mL) & 26.18 & 33.36 & 6.14 & & \\
\hline hs-CRP & $3.81 \pm$ & $8.02 \pm$ & $15.74 \pm$ & 133.729 & $<0.001$ \\
(mg/dL) & 0.85 & 2.05 & 3.39 & & \\
\hline cIMT & $0.636 \pm$ & $0.828 \pm$ & $1.152 \pm$ & 74.256 & $<0.001$ \\
& 0.103 & 0.176 & 0.163 & & \\
\hline
\end{tabular}

cIMT: carotid intima medial thickness; hs-CRP: high sensitive $\mathrm{C}$-reactive protein; $\mathrm{N}$ : number of subjects; TG: triglycerides; $\mathrm{P}<0.05$ : statistically significant; $\mathrm{P}$ $<0.01$ : highly statistically significant.

Post hoc test was done to confirm where the differences occurred between the three studied groups and it showed a highly significant difference between the control group (group C) \& patients with wellcontrolled diabetes (group W) regarding FPG, PPG, HA1c, hs-CRP, and cIMT, while no significant difference was found between the two groups regarding TG. There was a highly significant difference between patients with uncontrolled diabetes (group U) \& each of group $\mathrm{C}$ and group W regarding FPG, PPG, HA1c, hs-CRP, TG, and cIMT (Table 3). 
Table (3): Post hoc test to confirm where the differences occurred between the three studied groups

\begin{tabular}{|c|c|c|c|c|c|}
\hline \multirow[t]{2}{*}{\begin{tabular}{|l} 
Laboratory \\
parameter
\end{tabular}} & \multirow{2}{*}{\multicolumn{2}{|c|}{$\begin{array}{c}\text { Compared } \\
\text { groups }\end{array}$}} & \multicolumn{2}{|c|}{$\begin{array}{l}\text { 95\% Confidence } \\
\text { Interval }\end{array}$} & \multirow{3}{*}{$\begin{array}{c}\begin{array}{c}\mathbf{P} \\
\text { value }\end{array} \\
<0.001\end{array}$} \\
\hline & & & \multirow{2}{*}{$\begin{array}{l}\begin{array}{l}\text { Lower } \\
\text { Bound }\end{array} \\
-63.83 \\
\end{array}$} & \multirow{2}{*}{$\begin{array}{c}\begin{array}{c}\text { Upper } \\
\text { Bound }\end{array} \\
-34.73\end{array}$} & \\
\hline \multirow{3}{*}{$\begin{array}{l}\text { FPG (mg } \\
\text { /dL) }\end{array}$} & $\mathrm{C}$ & W & & & \\
\hline & $\mathrm{C}$ & $\mathrm{U}$ & -142.15 & -113.05 & $<0.001$ \\
\hline & $\mathrm{W}$ & & -92.87 & -63.77 & $<0.001$ \\
\hline \multirow{3}{*}{$\begin{array}{l}\text { PPG } \\
(\mathrm{mg} / \mathrm{dL})\end{array}$} & $\mathrm{C}$ & W & -99.0470 & -66.3130 & $<0.00$ \\
\hline & $\mathrm{C}$ & 0 & -237.5670 & -204.8330 & $<0.00$ \\
\hline & $\mathrm{W}$ & U & -154.8870 & -122.1530 & $<0.00$ \\
\hline & $\mathrm{C}$ & $\mathrm{W}$ & $\begin{array}{l}-1.7679 \\
\end{array}$ & -.8041 & $<0.00$ \\
\hline & $\mathrm{C}$ & $\mathrm{U}$ & -4.5455 & -3.5817 & $<0.00$ \\
\hline & $\mathrm{W}$ & 4 & -3.2595 & -2.2957 & $<0.00$ \\
\hline \multirow{3}{*}{$\begin{array}{l}\text { hs-CRP } \\
\text { (mg/dL) }\end{array}$} & $\mathrm{C}$ & W & -5.6869 & -2.7355 & $<0.00$ \\
\hline & $\mathrm{C}$ & & -13.4109 & -10.4595 & $<0.00$ \\
\hline & $\mathrm{W}$ & $\mathrm{U}$ & -9.1997 & -6.2483 & $<0.001$ \\
\hline \multirow{3}{*}{$\begin{array}{l}\text { TG } \\
(\mathrm{ng} / \mathrm{mL})\end{array}$} & $\mathrm{C}$ & $\mathrm{W}$ & -46.7596 & 1.6876 & .068 \\
\hline & $\mathrm{C}$ & $\mathrm{U}$ & -120.4916 & -72.0444 & $<0.001$ \\
\hline & $\mathrm{W}$ & $\mathrm{U}$ & -97.9556 & -49.5084 & $<0.00$ \\
\hline \multirow{3}{*}{ cIMT } & $\mathrm{C}$ & $\mathrm{W}$ & -.2774 & -.1066 & $<0.00$ \\
\hline & $\mathrm{C}$ & $U$ & -.6018 & -.4310 & $<0.00$ \\
\hline & $\mathrm{W}$ & $\mathrm{U}$ & -.4098 & -.2390 & $<0.00$ \\
\hline
\end{tabular}

HA1c: glycosylated hemoglobin; C: control group; cIMT: carotid intima medial thickness; FPG: fasting plasma glucose; hs-CRP: high sensitive C-reactive protein; PPG: 2 hour postprandial blood glucose; TG: triglycerides; $\mathrm{P}$ value $<0.05$ : statistically significant; $\mathrm{P}$ value $<0.01$ : highly statistically significant; U: uncontrolled diabetic group; W: wellcontrolled diabetic group

We studied the correlation between cIMT and each of age, BMI, SBP, DBP, duration of diabetes, FPG, PPG, A1c, hs-CRP, and TG levels. No significant difference was found between cIMT and all the studied parameters in the control group (Table 4).

Table (4): Correlation between cIMT and the studied parameters in the control group

\begin{tabular}{|l|c|c|}
\hline \multicolumn{1}{|c|}{$\begin{array}{c}\text { The studied } \\
\text { parameter }\end{array}$} & $\mathbf{R}$ & $\mathbf{P}$ \\
\hline Age (years) & -0.266 & 0.198 \\
\hline BMI (kg/m $\mathbf{m}^{\text {B }}$ & -0.031 & 0.881 \\
\hline $\begin{array}{l}\text { Systolic blood } \\
\text { pressure (mmHg) }\end{array}$ & -0.070 & 0.739 \\
\hline $\begin{array}{l}\text { Diastolic blood } \\
\text { pressure (mmHg) }\end{array}$ & -0.285 & 0.168 \\
\hline FPG (mg /dL) & 0.055 & 0.794 \\
\hline PPG (mg/dL) & 0.104 & 0.622 \\
\hline A1c & -0.198 & 0.343 \\
\hline TG (ng/mL) & -0.168 & 0.423 \\
\hline hs-CRP (mg /dL) & -0.175 & 0.403 \\
\hline
\end{tabular}

A1c: glycosylated hemoglobin; BMI: body mass index; cIMT: carotid intima medial thickness; FPG: fasting plasma glucose; hs-CRP: high sensitive C-reactive protein; PPG: 2 hour postprandial blood glucose; TG: triglycerides; $\mathrm{P}$ value < 0.05: statistically significant; $\mathrm{P}$ value $<0.01$ : highly statistically significant

In the well-controlled diabetic group, a highly significant positive correlation was found between cIMT and duration of diabetes but no significant correlations were found between cIMT and the rest of the studied parameters (Table 5).
Table (5): Correlation between cIMT and the studied parameters in the well-controlled diabetic group

\begin{tabular}{|l|c|c|}
\hline \multicolumn{1}{|c|}{$\begin{array}{c}\text { The studied } \\
\text { parameters }\end{array}$} & $\mathbf{R}$ & $\mathbf{P}$ \\
\hline Age (years) & 0.040 & 0.849 \\
\hline BMI (kg/m $\mathbf{2})$ & -0.022 & 0.916 \\
\hline $\begin{array}{l}\text { Systolic blood } \\
\text { pressure (mmHg) }\end{array}$ & 0.005 & 0.981 \\
\hline $\begin{array}{l}\text { Diastolic blood } \\
\text { pressure (mmHg) }\end{array}$ & 0.141 & 0.502 \\
\hline $\begin{array}{l}\text { Duration of DM } \\
\text { (mg /dL) }\end{array}$ & 0.78 & 0.004 \\
\hline FPG (mg /dL) & -0.027 & 0.900 \\
\hline PPG (mg/dL) & -0.029 & 0.890 \\
\hline A1c & -0.238 & 0.253 \\
\hline TG (ng/mL) & 0.317 & 0.123 \\
\hline hs-CRP (mg /dL) & 0.136 & 0.517 \\
\hline
\end{tabular}

HA1c: glycosylated hemoglobin; BMI: body mass index; cIMT: carotid intima medial thickness; FPG: fasting plasma glucose; hs-CRP: high sensitive Creactive protein; PPG: 2 hour postprandial blood glucose; TG: triglycerides; $\mathrm{P}$ value $<0.05$ : statistically significant; $\mathrm{P}$ value $<0.01$ : highly statistically significant

In the uncontrolled diabetic group, a highly significant positive correlation was found between cIMT and each of duration of diabetes, TG, and hs-CRP levels but no significant correlations were found between cIMT and the rest of the studied parameters (Table 6).

Table (6): Correlation between cIMT and the studied parameters in the uncontrolled diabetic group

\begin{tabular}{|l|c|c|}
\hline \multicolumn{1}{|c|}{ The studied parameters } & R & P \\
\hline Age (years) & 0.258 & 0.213 \\
\hline BMI (kg/m ${ }^{2}$ ) & -0.077 & 0.715 \\
\hline Systolic blood pressure (mmHg) & -0.310 & 0.131 \\
\hline Diastolic blood pressure (mmHg) & -0.265 & 0.201 \\
\hline Duration of DM (mg /dL) & 0.84 & 0.001 \\
\hline FPG (mg /dL) & -0.064 & 0.762 \\
\hline PPG (mg/dL) & -0.135 & 0.521 \\
\hline A1c & -0.048 & 0.819 \\
\hline TG $(\mathbf{n g} / \mathbf{m L})$ & 0.540 & 0.005 \\
\hline hs-CRP (mg /dL) & 0.646 & 0.001 \\
\hline
\end{tabular}

HA1c: glycosylated hemoglobin; BMI: body mass index; cIMT: carotid intima medial thickness; FPG: fasting plasma glucose; hs-CRP: high sensitive C-reactive protein; PPG: 2 hour postprandial blood glucose; TG: triglycerides; P value < 0.05: statistically significant; $\mathrm{P}$ value $<0.01$ : highly statistically significant.

\section{DISCUSSION}

Though the incidence of diabetes-related complications including cardiovascular disease is lower, people with diabetes still have a higher risk of vascular complications compared to individuals without diabetes ${ }^{(8)}$. Cardiovascular atherosclerosis remains the leading cause of death and disability among people with diabetes, especially those with $\mathrm{T} 2 \mathrm{DM}{ }^{(9)}$. 
So a cross-sectional study was performed on 75 individuals aged $\geq 40$ years to evaluate patients with T2DM for the presence of subclinical atherosclerosis and explore its correlation with hs-CRP and TG levels. 50 cases with T2DM were divided into two equal groups according to HA1c\% (well-controlled diabetics and uncontrolled diabetics). Another 25 healthy individuals represented the control group. In our study, there was a statistically significant difference regarding cIMT; being higher in type 2 diabetic patients, compared to the control subjects. Also, we found that cIMT in patients with uncontrolled diabetes is significantly higher than in those with well-controlled diabetes. This agrees with Baba et al. ${ }^{(\mathbf{1 0 )}}$ and Bashir $\boldsymbol{e t}$ al. ${ }^{(11)}$, who studied cIMT in patients with T2DM and found that cIMT is more common in diabetic patients than in non-diabetics.

Okeahialam et al. (12) compared cIMT among hypertensives, diabetics, and healthy individuals and found that there was a tendency towards increased cIMT from normal for the hypertensives and the diabetics, the latter more than the former, however, the difference didn't attain statistical significance. This variation may be due to differences in sample sizes, duration of diabetes, differences in demographics, comorbidities, method of measuring cIMT, and levels of glycemic control. In a systematic review by Brohall and Oden ${ }^{(13)}$, in 20 of 21 studies, the diabetic patients had greater cIMT than the individuals in the control groups. This variation may be due to differences in sample size, diabetes duration, and ultrasound method.

In the present study, TG, hs-CRP, and HAlc were significantly higher in uncontrolled diabetic patients compared to well-controlled diabetic patients. The same results were obtained by Kotb et al. ${ }^{(14)}$. In a study done by Hasan $\boldsymbol{e t}$ al. ${ }^{(15)}$ \& in a study done by Gangadhar and Muthahanumaiah (16), they found that TG levels were higher in uncontrolled diabetics than in controlled diabetics. King et al. ${ }^{(17)}$ who studied the relationship between glycemic control and CRP found that CRP is significantly higher in uncontrolled diabetics in comparison to well-controlled diabetics.

Our study showed a highly significant difference among the three studied groups in BMI; being highest in uncontrolled diabetics. In a study done

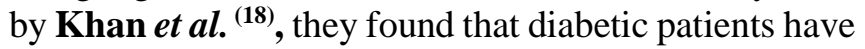
a higher BMI compared to non-diabetic populations. On the other hand, Bashir et al. ${ }^{(11)}$ found no significant difference in BMI between the diabetic and nondiabetic participants. The reason could be deferred to the difference in dietary habits and physical activity in the studied populations.

In our study, similar to Bashir et al. (11), neither the levels of fasting and postprandial blood glucose nor the level of HA1c were related to the cIMT. This observation is supported by the fact, as observed in the DCCT and UKPDS trials that although glycemic control has a definite role in delaying the occurrence and progression of microvascular complications, its effect on atherosclerosis and macrovascular complications is not well demonstrated ${ }^{(\mathbf{1 9})}$. Contrary to our results, some studies have shown a positive association between FPG and cIMT ${ }^{(\mathbf{2 0}, \mathbf{2 1})}$.

The disparity between the current study and previous studies concerning the association between glycemic indices (FPG, PPG, and HA1c) and cIMT might be explained by different populations included (i.e., the inclusion of those with normal blood glucose levels, those with diabetes or the entire population) and different designs (i.e., community-based, hospitalbased, or population-based) ${ }^{(22)}$.

The present study showed that age, BMI, systolic blood pressure, and diastolic blood pressure were not correlated with cIMT in all the studied groups. A highly significant positive correlation between cIMT and each of TG and hs-CRP levels was found only in the uncontrolled diabetic group. In both well-controlled and uncontrolled diabetic groups, cIMT has a highly significant positive correlation with the duration of diabetes. The strong correlation between cIMT and diabetes duration highlights the fact that long-term exposure to atherogenic factors associated with type 2 diabetes mellitus has a negative impact on arterial wall thickening ${ }^{(11)}$.

Bashir et al. ${ }^{(11)}$ found that in the diabetic participants there was a positive correlation between cIMT and each of age, systolic blood pressure, diastolic blood pressure, and duration of diabetes while no correlation was found between cIMT and each of BMI and TG. In the same study, the non-diabetic participants showed no correlation between cIMT and each of systolic blood pressure, diastolic blood pressure, and BMI but there was a positive correlation between cIMT and each of age and TG. In a Pakistani study conducted on patients with type 2 diabetes mellitus, an association was seen with the duration of diabetes mellitus and BMI while patient age, hypertension, and TG showed no association with cIMT ${ }^{(23)}$. A European study showed that patient' age and presence of hypertension were associated with an increased cIMT in newly diagnosed type 2 diabetes mellitus ${ }^{(24)}$.

Both Eldosoky et al. ${ }^{(25)}$ and Ali and Hadidi (26) in their studies, found a significant positive correlation between cIMT and hs-CRP. This association may be attributed to progressive inflammation in the ongoing atherosclerotic process. Schillinger et al. ${ }^{(27)}$ reported that the degree of inflammation measured by specific biomarkers may reflect the disease activity and can predict the progression of atherosclerosis. Therefore, acute-phase reactants as CRP may help as an indirect measure of the cytokine-dependent inflammatory process in the arterial wall.

In a meta-analysis of 21,000 patients done by Touboul et al. ${ }^{(28)}$, TG levels were positively associated with cIMT. On the other hand, Fitch et al. ${ }^{\text {(20) }}$ found no association between cIMT and TG. This variation can be explained by the difference in characteristics of the studied populations and different designs of the studies. 


\section{CONCLUSION}

Subclinical atherosclerosis is a common and frequent complication of type 2 diabetes mellitus. Duration of diabetes mellitus plays a role in this process. The parameters of glycemic control are not related to cIMT. TG and hs-CRP can be used as markers for subclinical atherosclerosis in patients with uncontrolled diabetes.

\section{ACKNOWLEDGEMENT: none to declare.}

\section{REFERENCES:}

1. International Diabetes Federation (2019) Diabetes Atlas, 9th edition. Available from: http://www.diabetesatlas.org.

2. Cho M, Park J, Nam J et al. (2008): Association of abdominal obesity with atherosclerosis in type 2 diabetes mellitus (T2DM) in Korea. J Korean Med Sci., 23: 781-788.

3. Papa G, Degano C, Iurato M et al. (2013): Macrovascular complication phenotypes in type 2 diabetic patients. Cardiovasc Diabetol., 12: 20.

4. Paneni F, Beckman J, Creager M et al. (2013): Diabetes and vascular disease: pathophysiology, clinical consequences, and medical therapy: part I, European Heart Journal, 34 (31): 2436-2443.

5. Amer M, Abdul-Rahman S, Gawad W et al. (2013): Relationship between peripheral arterial disease, carotid intima-media thickness and C-reactive protein in elderly diabetic patients. Advances in Aging Research, 2: 115-120.

6. Onut R, Balanescu AP, Constantinescu D et al. (2012): Imaging Atherosclerosis by Carotid Intima-media thickness in vivo: How to, Where and in Whom? Maedica, 7 (2): 153162.

7. Alizargar J, Bai C (2018): Factors associated with carotid Intima media thickness and carotid plaque score in community-dwelling and non-diabetic individuals. BMC Cardiovasc Disord., 18: 21.

8. Gregg EW, Li Y, Wang J et al. (2014): Changes in diabetes-related complications in the United States, 19902010. N. Engl. J. Med., 370 (16): 1514-1523.

9. Booth GL, Kapral MK, Fung K et al. (2006): Relation between age and cardiovascular disease in men and women with diabetes compared with nondiabetic people: a population-based retrospective cohort study. Lancet, 368: 29-36.

10. Baba M, Talle M, Ibinaiye P et al. (2018): Carotid IntimaMedia Thickness in Patients with Diabetes Mellitus Attending Tertiary Care Hospital in Nigeria. Angiol., 6: 210.

11.Bashir F, Nageen A, Kidwai S et al. (2017): Carotid intima-media thickness and cardiometabolic risk factors in Pakistani type 2 diabetics. Saudi J Health Sci., 6: 145-150.

12. Okeahialam B, Alonge B, Pam S et al. (2011): Carotid Intima Media Thickness as a measure of cardiovascular disease Burden in Nigerian Africans with Hypertension and Diabetes Mellitus. Int J Vasc Med., 32: 7171.

13. Brohall G, Oden A, Fagerberg B (2006): Carotid artery intima media thickness in patients with Type 2 diabetes mellitus and impaired glucose tolerance: a systematic review. Diabetic medicine, 23: 609-616.

14. Kotb N, Gaber R, Salama M et al. (2011): Clinical and biochemical predictors of increased carotid intima-media thickness in overweight and obese adolescents with type 2 diabetes. Diabetes \& Vascular Disease Research, 9 (1): 35 41.

15.Hasan C, Parial R, Islam M et al. (2014): Evaluation of biochemical parameters in controlled and uncontrolled type2 diabetic patients of Bangladesh. Int Res J Biol Sci., 3:1922.

16. Gangadhar M, Muthahanumaiah $\mathbf{N}$ (2020): Lipid profile among controlled and uncontrolled type-2 diabetic patients in a rural tertiary care center: a comparative study. Int $\mathbf{J}$ Basic Clin Pharmacol., 9: 562-565.

17. King D, Mainous A, Buchanan T et al. (2003): C-Reactive Protein and Glycemic Control in Adults With Diabetes. Diabetes Care, 26 (5): 1535-1539.

18. Khan M, Gruebner O, Kraemer A (2014): The geography of diabetes among the general adults aged 35 years and older in Bangladesh: Recent evidence from a cross-sectional survey. PLoS One, 9: e110756.

19. Nathan D, Genuth S, Lachin J et al. (1993): Diabetes Control and Complications Trial Research Group, The effect of intensive treatment of diabetes on the development and progression of long-term complications in insulindependent diabetes mellitus. N Engl J Med., 329: 977-986.

20.Fitch K, Stavrou E, Looby S et al. (2011): Association of cardiovascular risk factors with two surrogate markers of subclinical atherosclerosis: endothelial function and carotid intima media thickness. Atherosclerosis, 217: 437-440.

21. Mukai N, Ninomiya T, Hata J et al. (2015): Association of hemoglobin A1c and glycated albumin with carotid atherosclerosis in community-dwelling Japanese subjects: the Hisayama Study. Cardiovasc Diabetol., 14: 84.

22. Gao L, Bai L, Shi M et al. (2017): Association between carotid intima-media thickness and fasting blood glucose level: A population-based cross-sectional study among lowincome adults in rural China. Journal of diabetes investigation, 8 (6): 788-797.

23. Butt M, Zakaria M (2009): Association of common carotid intimal medial thickness (CCA-IMT) with risk factors of atherosclerosis in patients with type 2 diabetes mellitus. J Pak Med Assoc., 59: 590-593.

24. Frost D, Fröhlich B, Beischer W (2000): Subclinical arteriosclerosis in patients with newly diagnosed type 2 diabetes mellitus. Demonstration by high-resolution ultrasound measurements of intima-media thickness of the common carotid and femoral arteries. Dtsch Med Wochenschr., 125: 648-654.

25. Eldosoky M, Abdallah A, Eldesoky N et al. (2018): Role of Acute-phase Proteins (Orsomucoid 2 and hs-CRP) in Lean Type 2 Diabetic Patients with and without Subclinical Atherosclerosis. American Journal of Medicine and Medical Sciences, 8 (9): 219-225.

26. Ali T, Al Hadidi K (2013): Chemerin is associated with markers of inflammation and predictors of atherosclerosis in Saudi subjects with metabolic syndrome and type 2 diabetes mellitus. Beni-Suef Univ J Basic Appl Sci., 2: 86-95.

27. Schillinger M, Exner M, Mlekusch W et al. (2005): Inflammation and Carotid Artery--Risk for Atherosclerosis Study (ICARAS). Circulation, 111 (17): 2203-2209.

28. Touboul PJ, Labreuche J, Bruckert E et al. (2014): HDL-C, triglycerides and carotid IMT: a meta-analysis of 21,000 patients with automated edge detection IMT measurement. Atherosclerosis, 232 (1): 65-71. 